Maintenance and Safety of Aging Infrastructure 
Structures and Infrastructures Series

ISSN 1747-7735

Book Series Editor:

\section{Dan M. Frangopol}

Professor of Civil Engineering and

The Fazlur R. Khan Endowed Chair of Structural Engineering and Architecture Department of Civil and Environmental Engineering Center for Advanced Technology for Large Structural Systems (ATLSS Center) Lehigh University

Bethlehem, PA, USA

\section{Volume 10}




\section{Maintenance and Safety of Aging Infrastructure}

\section{Dan M. Frangopol and Yiannis Tsompanakis}


Cover illustration:

View of Brooklyn bridge maintenance, New York, USA

Photograph taken by Yiannis Tsompanakis, June 2013

Colophon

Book Series Editor:

Dan M. Frangopol

Volume Authors:

Dan M. Frangopol and Yiannis Tsompanakis

CRC Press/Balkema is an imprint of the Taylor \& Francis Group, an informa business

(C) 2014 Taylor \& Francis Group, London, UK

Typeset by MPS Ltd, Chennai, India

Printed and bound by CPI Group (UK) Ltd, Croydon, CRO 4YY

All rights reserved. No part of this publication or the information contained herein may be reproduced, stored in a retrieval system, or transmitted in any form or by any means, electronic, mechanical, by photocopying, recording or otherwise, without written prior permission from the publishers.

Although all care is taken to ensure integrity and the quality of this publication and the information herein, no responsibility is assumed by the publishers nor the author for any damage to the property or persons as a result of operation or use of this publication and/or the information contained herein.

British Library Cataloguing in Publication Data

A catalogue record for this book is available from the British Library

Library of Congress Cataloging-in-Publication Data

Maintenance and safety of aging infrastructure / edited by Dan M. Frangopol and Yiannis Tsompanakis.

pages $\mathrm{cm}$. - (Structures and infrastructures series, ISSN 1747-7735; volume 10)

Summary: "This edited volume presents the latest scientific research and application practice findings in the engineering field of maintenance and safety of aging infrastructure. The selected invited contributions will provide an overview of the use of advanced computational and/or experimental techniques in damage and vulnerability assessment as well as maintenance and retrofitting of aging structures and infrastructures (buildings, bridges, lifelines, etc) for minimization of losses and life-cycle-cost" — Provided by publisher.

Includes bibliographical references and index.

ISBN 978-0-4I5-65942-0 (hardback) — ISBN 978-0-203-38628-6 (ebook)

I. Structural dynamics-Data processing. 2. Structural engineering-Data processing.

3. Buildings-Maintenance and repair. 4. Bridges-Maintenance and repair.

I. Frangopol, Dan M., editor. II. Tsompanakis, Yiannis, 1969-editor.

TA654.M285 2014

624.1-dc23

Published by: CRC Press/Balkema

P.O. Box II320, 230I EH Leiden, The Netherlands

e-mail: Pub.NL@taylorandfrancis.com

www.crcpress.com - www.taylorandfrancis.com

ISBN: 978-0-4I5-65942-0 (Hbk)

ISBN: 978-0-203-38628-6 (e-book)

Structures and Infrastructures Series: ISSN 1747-7735

Volume 10

DOI: $10.1201 / \mathrm{b} 17073-1$

http://dx.doi.org/10.1201/b17073-1 


\section{Table of Contents}

Editorial

About the Book Series Editor

XIX

Preface

XXI

About the Editors

XXV

Contributors List

XXXV

Author Data

XXXVII

XLI

Chapter 1 Reliability-based Durability Design and Service Life Assessment of Concrete Structures in a Marine Environment

Mitsuyoshi Akiyama, Dan M. Frangopol and Hiroshi Matsuzaki

1.1 Introduction

1.2 Durability Design Criterion of RC Structures in a Marine Environment

1.2.1 Reliability Prediction

1.2.2 Durability Design Criterion based on Reliability

1.3 Life-Cycle Reliability Estimation of Deteriorated Existing RC Structures

1.3.1 Effect of Spatial Distribution of Rebar Corrosion on Flexural Capacity of RC Beams

1.3.2 Updating the Reliability of Existing RC Structures by Incorporating Spatial Variability

1.4 Conclusions

Chapter 2 Designing Bridges for Inspectability and Maintainability

Sreenivas Alampalli

2.1 Introduction

2.2 Bridge Inspection 28

2.3 Bridge Maintenance $\quad 31$

2.4 Role of Planning and Design 34

2.5 Designing for Inspectability and Maintainability 36

2.5.1 Bridge Type Selection 36

2.5.1.1 Redundancy 36

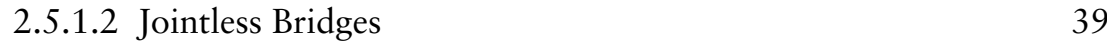

2.5.1.3 Weathering Steel $\quad 40$

$\begin{array}{ll}2.5 .1 .4 \text { Skew } & 40\end{array}$

2.5.1.5 Material Type $\quad 41$ 
2.5.2 Bridge Details

2.5.2.1 Bearings and Jacking Details 41

2.5.2.2 Deck Drainage and Scuppers $\quad 42$

2.5.2.3 Joints 43

$\begin{array}{ll}\text { 2.5.2.4 Steel Details } & 43\end{array}$

2.5.3 Access 44

2.5.3.1 Abutments and Piers $\quad 44$

2.5.3.2 Trusses and Arches $\quad 45$

2.5.3.3 Girder Bridges $\quad 47$

2.5.3.4 Bridge Railing and Fencing $\quad 47$

2.6 Complex, Unique and Signature Bridges 47

2.6.1 Specialized Procedures Requirement for Complex and
Unique Bridges

2.6.2 Movable Bridges $\quad 50$

2.6.3 Signature Bridges $\quad 51$

2.6.4 Bridge Security 52

2.7 Conclusions 52

2.8 References $\quad 53$

Chapter 3 Structural Vulnerability Measures for Assessment of Deteriorating Bridges in Seismic Prone Areas 55

Alice Alipour and Behrouz Shafei

3.1 Introduction

3.2 Numerical Modeling of Chloride Intrusion 56

$\begin{array}{ll}\text { 3.2.1 Evaporable Water Content } & 57\end{array}$

3.2.2 Chloride Binding Capacity $\quad 59$

3.2.3 Reference Chloride Diffusion Coefficient $\quad 62$

3.3 Chloride Diffusion Coefficient 63

3.3.1 Ambient Temperature $\quad 63$

$\begin{array}{ll}\text { 3.3.2 Relative Humidity } & 64\end{array}$

$\begin{array}{ll}\text { 3.3.3 Age of Concrete } & 67\end{array}$

$\begin{array}{ll}\text { 3.3.4 Free Chloride Content } & 67\end{array}$

3.4 Estimation of Corrosion Initiation Time $\quad 68$

3.5 Extent of Structural Degradation $\quad 71$

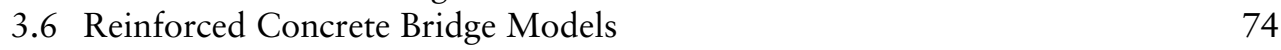

$\begin{array}{ll}\text { 3.6.1 Material Properties } & 76\end{array}$

$\begin{array}{ll}3.6 .2 \text { Superstructure } & 76\end{array}$

$\begin{array}{ll}3.6 .3 \text { Columns } & 77\end{array}$

$\begin{array}{ll}3.6 .4 \text { Abutments } & 77\end{array}$

$\begin{array}{ll}\text { 3.6.5 Foundation } & 78\end{array}$

3.7 Structural Capacity Evaluation of Deteriorating Bridges 79

3.8 Seismic Performance of Deteriorating Bridges 82

3.8.1 Probabilistic Life-Time Fragility Analysis 83

3.8.2 Seismic Vulnerability Index for Deteriorating Bridges 88

3.9 Conclusions 92

3.10 References $\quad 92$ 
Chapter 4 Design Knowledge Gain by Structural Health Monitoring 95

Stefania Arangio and Franco Bontempi

4.1 Introduction

4.2 Knowledge and Design 96

4.3 System Engineering Approach \& Performance-based Design 99

4.4 Structural Dependability 102

4.5 Structural Health Monitoring 105

4.5.1 Structural Identification 107

4.5.2 Neural Network-based Data Processing 108

4.6 Knowledge Gain by Structural Health Monitoring: A Case Study 109

4.6.1 Description of the Considered Bridge and Its

Monitoring System 109

4.6.2 Application of the Enhanced Frequency Domain Decomposition $\quad 110$

4.6.3 Application of a Neural Networks-based Approach 113

$\begin{array}{ll}4.7 \text { Conclusions } & 117\end{array}$

$\begin{array}{ll}4.8 \text { References } & 117\end{array}$

Chapter 5 Emerging Concepts and Approaches for Efficient and Realistic Uncertainty Quantification

Michael Beer, Ioannis A. Kougioumtzoglou and Edoardo Patelli

5.1 Introduction

122

122

5.2.1 General Remarks Civil Engineering

123

5.2.2.1 Spectral Analysis: The Fourier Transform 123

5.2.2.2 Non-Stationary Spectral Analysis 124

5.2.3 Spectral Analysis Subject to Limited and/or Missing Data 126

5.2.3.1 Fourier Transform with Zeros 126

5.2.3.2 Clean Deconvolution 126

5.2.3.3 Autoregressive Estimation 126

5.2.3.4 Least Squares Spectral Analysis 126

5.2.3.5 Artificial Neural Networks: A Potential Future Research Path

5.2.4 Path Integral Techniques for Efficient Response Determination and Reliability Assessment of Civil Engineering Structures and Infrastructure

5.2.4.1 Numerical Path Integral Techniques: Discrete Chapman-Kolmogorov Equation Formulation

5.2.4.2 Approximate/Analytical Wiener Path Integral Techniques

5.3 Generalised Uncertainty Models 129

5.3.1 Problem Description 129

5.3.2 Classification of Uncertainties 130

5.3.3 Imprecise Probability 131

5.3.4 Engineering Applications of Imprecise Probability 132 
5.3.5 Fuzzy Probabilities

5.3.6 Engineering Applications of Fuzzy Probability 141

5.4 Monte Carlo Techniques

5.4.1 General Remarks

5.4.2 History of Monte Carlo and Random Number Generators 142 5.4.2.1 Random Number Generator 143

5.4.3 Realizations of Random Variables and Stochastic Processes 143

$\begin{array}{ll}\text { 5.4.4 Evaluation of Integrals } & 145\end{array}$

$\begin{array}{ll}\text { 5.4.5 Advanced Methods and Future Trends } & 146\end{array}$ $\begin{array}{ll}\text { 5.4.5.1 Sequential Monte Carlo } & 147\end{array}$

$\begin{array}{ll}\text { 5.4.6 High Performance Computing } & 149\end{array}$

$\begin{array}{ll}\text { 5.4.7 Approaches to Lifetime Predictions } & 150\end{array}$

5.4.7.1 Monte Carlo Simulation of Crack Initiation 151

5.4.7.2 Monte Carlo Simulation of Crack Propagation 151

5.4.7.3 Monte Carlo Simulation of Other Degradation Processes 152

5.4.7.4 Lifetime Prediction and Maintenance Schedules 152

5.5 Conclusions

153

$\begin{array}{ll}5.6 \text { References } & 154\end{array}$

Chapter 6 Time-Variant Robustness of Aging Structures 163

Fabio Biondini and Dan M. Frangopol
6.1 Introduction

6.2 Damage Modeling 165

$\begin{array}{lc}\text { 6.2.1 Deterioration Patterns } & 166\end{array}$

$\begin{array}{ll}\text { 6.2.2 Deterioration Rate } & 167\end{array}$

6.2.3 Local and Global Measures of Damage 168

$\begin{array}{ll}\text { 6.3 Structural Performance Indicators } & 169\end{array}$

$\begin{array}{ll}\text { 6.3.1 Parameters of Structural Behavior } & 169\end{array}$

$\begin{array}{lc}\text { 6.3.2 Pseudo-Loads } & 170\end{array}$

$\begin{array}{ll}\text { 6.3.3 Failure Loads and Failure Times } & 172\end{array}$

6.4 Measure of Structural Robustness $\quad 173$

6.5 Role of Performance Indicators and Structural Integrity 174

$\begin{array}{ll}\text { 6.5.1 A Comparative Study } & 174\end{array}$

$\begin{array}{ll}\text { 6.5.2 Structural Integrity Index } & 177\end{array}$

$\begin{array}{ll}\text { 6.6 Damage Propagation } & 178\end{array}$

$\begin{array}{ll}\text { 6.6.1 Propagation Mechanisms } & 178\end{array}$

$\begin{array}{ll}\text { 6.6.2 Fault-Tree Analysis } & 179\end{array}$

6.7 Structural Robustness and Progressive Collapse $\quad 179$

6.8 Structural Robustness and Static Indeterminacy 182

6.9 Structural Robustness, Structural Redundancy and Failure Times 186

$\begin{array}{ll}\text { 6.9.1 Case Study } & 188\end{array}$

$\begin{array}{ll}\text { 6.9.2 Corrosion Damage and Failure Loads } & 188\end{array}$

$\begin{array}{lr}\text { 6.9.3 Robustness and Redundancy } & 189\end{array}$

$\begin{array}{ll}\text { 6.9.4 Failure Times } & 193\end{array}$

6.10 Role of Uncertainty and Probabilistic Analysis 194

6.11 Conclusions 196

$\begin{array}{ll}\text { 6.12 References } & 197\end{array}$ 
Chapter 7 Extending Fatigue Life of Bridges Beyond 100 Years by using Monitored Data

Eugen Brühwiler

7.1 Introduction

7.2 Proposed Approach 202

7.2.1 Introduction 202

7.2.2 Structural Safety Verification Format 203

7.2.3 Determination of Updated Action Effect 203

7.2.4 Safety Requirements 204

7.3 Case Study of a Riveted Railway Bridge 205

7.3.1 Description of the Bridge 205

7.3.2 Model for Structural Analysis 205

7.3.3 Monitoring 206

7.3.4 Fatigue Safety Verification 207

7.3.4.1 Step 1: Fatigue Safety Verification with Respect to the Fatigue Limit 209

7.3.4.2 Step 2: Fatigue Damage Accumulation Calculation and Fatigue Safety Verification

7.3.5 Discussion of the Results

7.4 Case Study of a Highway Bridge Deck in

Post-tensioned Concrete

7.4.1 Motivation 211

7.4.2 Monitoring System 212

7.4.3 Investigation of Extreme Action Effects 213

7.4.4 Investigation of Fatigue Action Effects 213

7.4.5 Discussion of the Results 213

$\begin{array}{ll}7.5 \text { Conclusions } & 214\end{array}$

$\begin{array}{ll}7.6 \text { References } & 214\end{array}$

Chapter 8 Management and Safety of Existing Concrete Structures via Optical Fiber Distributed Sensing Joan R. Casas, Sergi Villalba and Vicens Villalba

8.1 Introduction

8.2 OBR Technology: Description and Background 219

8.3 Application to Concrete Structures 221

8.3.1 Laboratory Test in a Reinforced Concrete Slab 222

8.3.1.1 OBR Sensors Application 223

8.3.2 Prestressed Concrete Bridge 228

8.3.2.1 Reading Strains under $400 \mathrm{kN}$ Truck 230

8.3.2.2 Reading Strains under Normal Traffic and $400 \mathrm{kN}$ Static Load

8.3.3 Concrete Cooling Tower 233

8.3.3.1 OBR Sensors Application 236

8.4 Results and Discussion 241

8.5 Conclusions 243

8.6 References 244 
Chapter 9 Experimental Dynamic Assessment of Civil Infrastructure

Álvaro Cunha, Elsa Caetano, Filipe Magalhães and

Carlos Moutinho

9.1 Dynamic Testing and Continuous Monitoring of Civil Structures 247

9.2 Excitation and Vibration Measurement Devices 248

9.3 Modal Identification 251

9.3.1 Overview of EMA and OMA Methods 251

$\begin{array}{ll}\text { 9.3.2 Pre-processing } & 253\end{array}$

9.3.3 Frequency Domain Decomposition 254

9.3.4 Stochastic Subspace Identification 256

9.3.5 Poly-reference Least Squares Frequency Domain 260

9.4 Mitigation of Environmental Effects on Modal Estimates and

Vibration Based Damage Detection

264

9.5 Examples of Dynamic Testing and Continuous

$\begin{array}{ll}\text { Dynamic Monitoring } & 267\end{array}$

$\begin{array}{ll}\text { 9.5.1 Dynamic Testing } & 267\end{array}$

$\begin{array}{ll}\text { 9.5.2 Continuous Dynamic Monitoring } & 270\end{array}$

9.5.2.1 Continuous Monitoring of Pedro e Inês

Lively Footbridge

270

9.5.2.2 Continuous Monitoring of Infante

D. Henrique Bridge

274

9.5.2.3 Continuous Monitoring of Braga Stadium Suspension Roof

277

283

9.6 Conclusions

285

Chapter 10 Two Approaches for the Risk Assessment of Aging Infrastructure with Applications

David De Leon Escobedo, David Joaquín Delgado-Hernandez and Juan Carlos Arteaga-Arcos

10.1 Introduction

10.2 Use of the Expected Life-Cycle Cost to Derive Inspection Times and Optimal Safety Levels

10.2.1 Highway Concrete Bridge in Mexico

10.2.2 Oil Offshore Platform in Mexico

10.2.2.1 Assessment of Structural Damage

10.2.2.2 Initial, Damage and Life-Cycle Cost

10.2.2.3 Optimal Design of an Offshore Platform

10.2.2.4 Effects of Epistemic Uncertainties 298

10.2.2.5 Minimum Life-Cycle Cost Designs 298

10.3 Using Bayesian Networks to Assess the Economical Effectiveness of

Maintenance Alternatives

10.3.1 Bayesian Networks

10.3.2 BN for the Risk Assessment of Earth Dams in

Central Mexico

10.4 Conclusions and Recommendations 303

10.5 References 
Chapter 11 Risk-based Maintenance of Aging Ship Structures 307

Yordan Garbatov and Carlos Guedes Soares

11.1 Introduction

11.2 Corrosion Deterioration Modelling 309

11.3 Nonlinear Corrosion Wastage Model Structures 312

11.3.1 Corrosion Wastage Model Accounting for Repair 315

11.3.2 Corrosion Wastage Model Accounting for the Environment 316

11.3.3 Corrosion Degradation Surface Modelling 320

$\begin{array}{ll}11.4 \text { Risk-based Maintenance Planning } & 324\end{array}$

11.4.1 Analysing Failure Data 325

11.4.2 Optimal Replacement - Minimization of Cost 327

11.4.3 Optimal Replacement - Minimization of Downtime 329

11.4.4 Optimal Inspection to Maximize the Availability 330

11.4.5 Comparative Analysis of Corroded Deck Plates 332

11.4.6 Risk-based Maintenance of Tankers and Bulk Carriers 333

$\begin{array}{ll}11.5 \text { Conclusions } & 337\end{array}$

11.6 References 337

Chapter 12 Investigating Pavement Structure Deterioration with a Relative Evaluation Model

Kiyoyuki Kaito, Kiyoshi Kobayashi and Kengo Obama

12.1 Introduction

12.2 Framework of the Study 344

12.2.1 Deterioration Characteristics of the Pavement Structure 344

12.2.2 Benchmarking and Relative Evaluation 346

12.3 Mixed Markov Deterioration Hazard Model 347

12.3.1 Preconditions for Model Development 347

12.3.2 Mixed Markov Deterioration Hazard Model 348

12.3.3 Estimation of a Mixed Markov Deterioration Hazard Model 351

12.3.4 Estimation of the Heterogeneity Parameter 353

12.4 Benchmarking and Evaluation Indicator 355

12.4.1 Benchmarking Evaluation $\quad 355$

12.4.2 Road Surface State Inspection and Benchmarking 355

12.4.3 Relative Evaluation and the Extraction of Intensive Monitoring Sections 356

12.4.4 FWD Survey and the Diagnosis of the Deterioration of a Pavement Structure $\quad 357$

12.5 Application Study 358

12.5.1 Outline 358

12.5.2 Estimation Results 359

12.5.3 Relative Evaluation of Deterioration Rate 362

12.5.4 FWD Survey for Structural Diagnosis 365

12.5.5 Relation between the Heterogeneity Parameter and the Results of the FWD Survey 370

12.5.6 Perspectives for Future Studies 375

12.6 Conclusions 376

12.7 References 377 
Chapter 13 Constructs for Quantifying the Long-term Effectiveness of Civil Infrastructure Interventions

Steven Lavrenz, Jackeline Murillo Hoyos and Samuel Labi

13.1 Introduction

13.2 The Constructs for Measuring Interventions Effectiveness 381

13.2.1 Life of the Intervention 382

13.2.1.1 Age-based Approach $\quad 383$

13.2.1.2 Condition-based Approach 384

13.2.1.3 The Issue of Censoring and Truncation on the Age- and Condition-based Approaches

13.2.2 Extension in the Life of the Infrastructure due to the Intervention

13.2.3 Increase in Average Performance of the Infrastructure over the Intervention Life

13.2.4 Increased Area Bounded by Infrastructure Performance Curve due to the Intervention

13.2.5 Reduction in the Cost of Maintenance or Operations Subsequent to the Intervention

13.2.6 Decrease in Initiation Likelihood or Increase in Initiation Time of Distresses

400

13.3 Conclusions

403

13.4 References

403

Chapter 14 Risk Assessment and Wind Hazard Mitigation of Power Distribution Poles

Yue Li, Mark G. Stewart and Sigridur Bjarnadottir

14.1 Introduction

14.2 Design of Distribution Poles

408

14.3 Design (Nominal) Load $\left(\mathrm{S}_{\mathrm{n}}\right)$

409

14.4 Design (Nominal) Resistance $\left(R_{n}\right)$ and Degradation of

Timber Poles

409

14.5 Hurricane Risk Assessment of Timber Poles

410

14.6 Hurricane Mitigation Strategies and Their Cost-effectiveness

412

14.6.1 Mitigation Strategies

14.6.2 Cost of Replacement $\left(\mathrm{C}_{\text {rep }}\right)$ and Annual Replacement Rate $(\delta)$

412

14.6.3 Life Cycle Cost Analysis (LCC) for Cost-effectiveness Evaluation

14.7 Illustrative Example

14.7.1 Design

415

14.7.2.1 Hurricane Fragility

14.7.2.2 Updated Annual $\mathrm{p}_{\mathrm{f}}$ Considering Effects of Degradation and Climate Change

14.7.3 Cost-effectiveness of Mitigation Strategies 418

14.8 Conclusions

424

14.9 References 
Chapter 15 A Comparison between MDP-based Optimization Approaches for Pavement Management Systems

Aditya Medury and Samer Madanat

15.1 Introduction

15.2 Methodology

15.2.1 Top-Down Approach

432

15.2.2 Bottom-Up Approaches

15.2.2.1 Two Stage Bottom-Up Approach

15.2.2.2 Modified Two Stage Bottom-Up Approach:

Incorporating Lagrangian Relaxation Methods

15.2.3 Obtaining Facility-Specific Policies using Top-Down Approach:

A Simultaneous Network Optimization Approach

15.3 Parametric Study

15.3.1 Results

443

15.3.2 Implementation Issues

445

15.4 Conclusions and Future Work

445

15.5 References

Chapter 16 Corrosion and Safety of Structures in Marine Environments Robert E. Melchers

16.1 Introduction

16.2 Structural Reliability Theory

16.3 Progression of Corrosion with Time

453

16.4 Plates, Ships, Pipelines and Sheet Piling

456

16.5 Mooring Chains

459

16.6 Extreme Value representation of Maximum Pit Depth Uncertainty

461

16.7 Effect of Applying the Frechet Extreme Value Distribution

463

16.8 Discussion of the Results

464

16.9 Conclusions

465

16.10 References

Chapter 17 Retrofitting and Refurbishment of Existing Road Bridges

Claudio Modena, Giovanni Tecchio, Carlo Pellegrino, Francesca da Porto, Mariano Angelo Zanini and Marco Donà

17.1 Introduction

17.2 Retrofitting and Refurbishment of Common RC Bridge Typologies

17.2.1.1 Concrete Deterioration due to Water Penetration

17.2.1.2 Cracking and Spalling of Concrete Cover due to Carbonation and Bar Oxidation

17.2.2 Original Design and Construction Defects

17.2.3 Rehabilitation and Retrofit of Existing RC Bridges

17.2.3.1 Rehabilitation and Treatment of the Deteriorated Surfaces 
17.3 Assessment and Retrofitting of Common Steel Bridge Typologies $\quad 509$

17.3.1 Original Design Defects - Fatigue Effects 509

17.3.2 Degradation Processes $\quad 512$

17.3.3 Rehabilitation and Retrofit of the Existing Steel Decks 515

17.3.3.1 Repair Techniques for Corroded Steel Members $\quad 515$

17.3.3.2 Rehabilitation and Strengthening Techniques for Fatigue-induced Cracks 517

17.4 Assessment and Retrofitting of Common Masonry Bridge Typologies 519

17.4.1 Degradation Processes and Original Design Defects 520

17.4.2 Rehabilitation and Retrofit of Existing Masonry Arch

Bridges

524

17.4.2.1 Barrel Vault $\quad 524$

17.4.2.2 Spandrel Walls, Piers, Abutments and Foundations $\quad 525$

17.5 Conclusions

529

$\begin{array}{lll}17.6 & \text { References } & 531\end{array}$

Chapter 18 Stochastic Control Approaches for Structural Maintenance 535

Konstantinos G. Papakonstantinou and Masanobu Shinozuka

18.1 Introduction 535

18.2 Discrete Stochastic Optimal Control with Full Observability 537

$\begin{array}{ll}\text { 18.2.1 State Augmentation } & 540\end{array}$

18.3 Stochastic Optimal Control with Partial Observability 541

$\begin{array}{ll}\text { 18.3.1 Bellman Backups } & 544\end{array}$

18.4 Value Function Approximation Methods 546

18.4.1 Approximations based on MDP and Q-functions 547

$\begin{array}{ll}\text { 18.4.2 Grid-based Approximations } & 547\end{array}$

$\begin{array}{ll}\text { 18.4.3 Point-based Solvers } & 549\end{array}$

18.4.3.1 Perseus Algorithm $\quad 549$

18.5 Optimum Inspection and Maintenance Policies with POMDPs 552

18.5.1 POMDP Modeling $\quad 553$

18.5.1.1 States and Maintenance Actions 553

18.5.1.2 Observations and Inspection Actions $\quad 556$

$\begin{array}{ll}\text { 18.5.1.3 Rewards } & 558\end{array}$

18.5.1.4 Joint Actions and Summary $\quad 559$

$\begin{array}{llr}18.6 & \text { Results } & 560\end{array}$

18.6.1 Infinite Horizon Results $\quad 560$

18.6.2 Finite Horizon Results $\quad 565$

$\begin{array}{lll}18.7 & \text { Conclusions } & 569\end{array}$

$\begin{array}{lll}18.8 \text { References } & 570\end{array}$

Chapter 19 Modeling Inspection Uncertainties for On-site Condition Assessment using NDT Tools 573

$\begin{array}{ll}\text { Franck Schoefs } & 573\end{array}$

$\begin{array}{ll}\text { 19.1 Introduction } & 573 \\ \text { 19.2 } & \text { Uncertainty Identification and Modeling during Inspection }\end{array}$

$\begin{array}{ll}\text { 19.2 Uncertainty Identification and Modeling during Inspection } & 576 \\ \text { 19.2.1 Sources of Uncertainties: From the Tool to the Decision } & 576\end{array}$

19.2.1.1 Aleatory Uncertainties $\quad 576$

19.2.1.2 Epistemic Uncertainties $\quad 577$ 
19.2.2 Epistemic and Aleatory Uncertainty Modelling

19.2.2.1 Probabilistic Modeling of PoD and PFA from

Signal Theory

19.2.2.2 Probabilistic Assessment of PoD and PFA from Statistics (Calibration)

19.2.2.3 The ROC Curve as Decision Aid-Tool and Method for Detection Threshold Selection: The $\alpha-\delta$ Method

19.2.2.4 Case of Multiple Inspections

19.2.2.5 Spatial and Time Dependence of ROC Curves and Detection Threshold for Degradation Processes

19.3 Recent Concepts for Decision

19.3.1 Bayesian Modeling for Introducing New Quantities 601

19.3.2 Discussion on the Assessment of PCE 604

19.3.3 Definition of the Cost Function for a Risk Assessment 604

19.3.3.1 Modelling and Illustration $\quad 604$

19.3.3.2 Use of the $\alpha-\delta$ Method 607

19.3.4 Definition of a Two Stage Inspection Model 610

19.4 Recent Developpements about Spatial Fields Assesment and

Data Fusion

614

19.5 Summary

615

19.6 References

Chapter 20 The Meaning of Condition Description and Inspection Data Quality in Engineering Structure Management

20.1 Introduction Marja-Kaarina Söderqvist

20.2 Engineering Structures

20.3 The Inspection System

20.3.1 General Description

20.3.2 Goals of Inspection

20.3.3 Inspection Types and Intervals

20.3.4 Handbooks and Guidelines

20.3.5 Inspection Data

624

20.3.6 Use of Inspection Results

20.4 Condition Indicators

20.4.2 Data Estimated in Inspections $\quad 627$

20.4.3 Data Processed by the Owner 628

20.5 The Management of Bridge Inspection Data Quality 628

20.5.1 General Rules

20.5.2 Tools for Data Quality Control 628

20.5.3 Training of Inspectors $\quad 629$

20.5.4 Quality Measurement Process: A Case Application $\quad 630$

20.5.4.1 Bridge Inspector Qualifications 630

20.5.4.2 Day for Advanced Training $\quad 630$

20.5.4.3 Quality Measurements $\quad 632$

20.5.4.4 Quality Reports of the Bridge Register 633

20.5.4.5 Follow up of Quality Improvement Methods 633 
20.6 Prediction of Structure Condition $\quad 635$

20.6.1 Age Behaviour Modelling 635

20.6.2 The Finnish Reference Bridges $\quad 636$

20.6.2.1 Model Simulation 636

20.7 Maintenance, Repair and Rehabilitation Policy 637

20.7.1 Goals and Targets 637

20.7.2 Central Policy Definitions in the Management Process 638

20.7.3 Maintenance and Repair Planning 638

20.8 Conclusions $\quad 639$

20.9 References 639

Chapter 21 Climate Adaptation Engineering and Risk-based Design and Management of Infrastructure

641

Mark G. Stewart, Dimitri V. Val, Emilio Bastidas-Arteaga, Alan O'Connor and Xiaoming Wang

21.1 Introduction

21.2 Modelling Weather and Climate-related Hazards in Conditions of Climate Change

21.2.1 Climate Modelling

21.2.2 Modelling Extreme Events under Non-Stationary Conditions

21.2.2.1 Generalised Extreme Value Distribution for Block Maxima

21.2.2.2 Generalised Pareto Distribution for Threshold Exceedance

21.2.2.3 Point Process Characterisation of Extremes

21.3 Impacts of Climate Change

21.3.1 Corrosion and Material Degradation

21.3.3 Sustainability and Embodied Energy Requirements for

Maintenance Strategies

21.4 Risk-based Decision Support

21.4.1 Definition of Risk

21.4.2 Cost-Effectiveness of Adaptation Strategies 658

21.5 Case Studies of Optimal Design and Management of Infrastructure

21.5.1 Resilience of Interdependent Infrastructure Systems to Floods

21.5.2 Strengthening Housing in Queensland Against Extreme Wind

21.5.3 Climate Change and Cost-Effectiveness of Adaptation Strategies in RC Structures Subjected to Chloride Ingress

21.5.4 Designing On- and Offshore Wind Energy Installations to Allow for Predicted Evolutions in Wind and Wave Loading

21.7 Conclusions 678

21.8 References 678 
Chapter 22 Comparing Bridge Condition Evaluations with

Life-Cycle Expenditures

Bojidar Yanev

22.1 Introduction: Networks and Projects

685

22.2 Network and Project Level Condition Assessments 686

22.2.1 Potential Hazards (NYS DOT) 688

22.2.2 Load Rating (AASHTO, 2010) 688

$\begin{array}{ll}\text { 22.2.3 Vulnerability (NYS DOT) } & 689\end{array}$

22.2.4 Serviceability and Sufficiency (NBI) $\quad 689$

$\begin{array}{ll}22.2 .5 \text { Diagnostics } & 690\end{array}$

22.3 Bridge-Related Actions $\quad 690$

22.3.1 Maintenance $\quad 691$

22.3.2 Preservation $\quad 692$

22.3.3 Repair and Rehabilitation $\quad 692$

22.4 The New York City Network - Bridge Equilibrium of Supply/Demand 692

22.5 Network Optimization/Project Prioritization 694

22.5.1 The Preventive Maintenance Model 695

$\begin{array}{ll}22.5 .2 \text { The repair model } & 701\end{array}$

$\begin{array}{lll}22.6 & \text { Conclusions } & 703\end{array}$

$\begin{array}{lll}22.7 & \text { References } & 704\end{array}$

Chapter 23 Redundancy-based Design of Nondeterministic Systems 707

Benjin Zhu and Dan M. Frangopol

23.1 Introduction

707

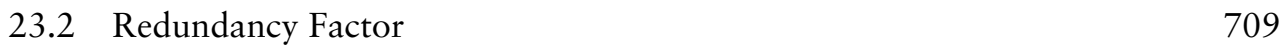

$\begin{array}{ll}\text { 23.2.1 Definition } & 709\end{array}$

$\begin{array}{ll}\text { 23.2.2 Example } & 709\end{array}$

23.3 Effects of Parameters on Redundancy Factor $\quad 711$

23.4 Redundancy Factors of Systems with Many Components 719

$\begin{array}{ll}23.4 .1 \text { Using the RELSYS program } & 719\end{array}$

$\begin{array}{ll}\text { 23.4.2 Using the MCS-based program } & 721\end{array}$

23.5 Limit States for Component Design 726

23.6 A Highway Bridge Example 728

23.6.1 Live Load Bending Moments $\quad 729$

23.6.2 Dead Load Moments $\quad 730$

23.6.3 Mean Resistance of Girders $\quad 730$

23.6.4 An Additional Case: $\beta_{\text {sys,target }}=4.0 \quad 733$

23.7 Conclusions $\quad 735$

23.8 References $\quad 736$

Author Index $\quad 739$

Subject Index $\quad 741$

Structures and Infrastructures Series $\quad 745$ 


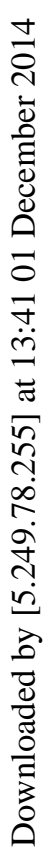




\section{Editorial}

Welcome to the Book Series Structures and Infrastructures.

Our knowledge to model, analyze, design, maintain, manage and predict the lifecycle performance of structures and infrastructures is continually growing. However, the complexity of these systems continues to increase and an integrated approach is necessary to understand the effect of technological, environmental, economical, social and political interactions on the life-cycle performance of engineering structures and infrastructures. In order to accomplish this, methods have to be developed to systematically analyze structure and infrastructure systems, and models have to be formulated for evaluating and comparing the risks and benefits associated with various alternatives. We must maximize the life-cycle benefits of these systems to serve the needs of our society by selecting the best balance of the safety, economy and sustainability requirements despite imperfect information and knowledge.

In recognition of the need for such methods and models, the aim of this Book Series is to present research, developments, and applications written by experts on the most advanced technologies for analyzing, predicting and optimizing the performance of structures and infrastructures such as buildings, bridges, dams, underground construction, offshore platforms, pipelines, naval vessels, ocean structures, nuclear power plants, and also airplanes, aerospace and automotive structures.

The scope of this Book Series covers the entire spectrum of structures and infrastructures. Thus it includes, but is not restricted to, mathematical modeling, computer and experimental methods, practical applications in the areas of assessment and evaluation, construction and design for durability, decision making, deterioration modeling and aging, failure analysis, field testing, structural health monitoring, financial planning, inspection and diagnostics, life-cycle analysis and prediction, loads, maintenance strategies, management systems, nondestructive testing, optimization of maintenance and management, specifications and codes, structural safety and reliability, system analysis, time-dependent performance, rehabilitation, repair, replacement, reliability and risk management, service life prediction, strengthening and whole life costing.

This Book Series is intended for an audience of researchers, practitioners, and students world-wide with a background in civil, aerospace, mechanical, marine and automotive engineering, as well as people working in infrastructure maintenance, monitoring, management and cost analysis of structures and infrastructures. Some volumes are monographs defining the current state of the art and/or practice in the field, and some are textbooks to be used in undergraduate (mostly seniors), graduate and 
postgraduate courses. This Book Series is affiliated to Structure and Infrastructure Engineering (http://www.informaworld.com/sie), an international peer-reviewed journal which is included in the Science Citation Index.

It is now up to you, authors, editors, and readers, to make Structures and Infrastructures a success.

Dan M. Frangopol

Book Series Editor 


\section{About the Book Series Editor}

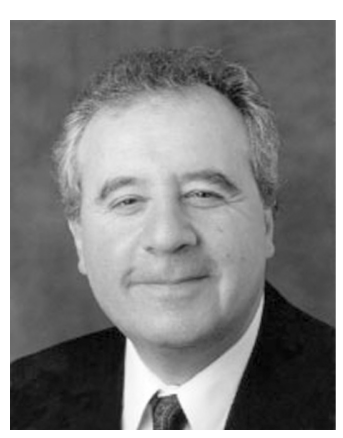

Dr. Dan M. Frangopol is the first holder of the Fazlur R. Khan Endowed Chair of Structural Engineering and Architecture at Lehigh University, Bethlehem, Pennsylvania, USA, and a Professor in the Department of Civil and Environmental Engineering at Lehigh University. He is also an Emeritus Professor of Civil Engineering at the University of Colorado at Boulder, USA, where he taught for more than two decades (1983-2006). Before joining the University of Colorado, he worked for four years (1979-1983) in structural design with A. Lipski Consulting Engineers in Brussels, Belgium. In 1976, he received his doctorate in Applied Sciences from the University of Liège, Belgium, and holds three honorary doctorates (Doctor Honoris Causa) from the Technical University of Civil Engineering in Bucharest, Romania, the University of Liège, Belgium, and the Gheorghe Asachi Technical University of Iași, Romania.

Dr. Frangopol is an Honorary Professor at seven universities (Hong Kong Polytechnic, Tongji, Southeast, Tianjin, Dalian, Chang'an and Harbin Institute of Technology), and a Visiting Chair Professor at the National Taiwan University of Science and Technology. He is a Distinguished Member of the American Society of Civil Engineers (ASCE), Inaugural Fellow of both the Structural Engineering Institute and the Engineering Mechanics Institute of ASCE, Fellow of the American Concrete Institute (ACI), Fellow of the International Association for Bridge and Structural Engineering (IABSE), and Fellow of the International Society for Health Monitoring of Intelligent Infrastructures (ISHMII). He is also an Honorary Member of the Romanian Academy of Technical Sciences, President of the International Association for Bridge Maintenance and Safety (IABMAS), Honorary Member of the Portuguese Association for Bridge Maintenance and Safety (IABMAS-Portugal Group), Honorary Member of the IABMAS-China Group, and Honorary President of both IABMAS-Italy and IABMAS-Brazil Groups.

Dr. Frangopol is the initiator and organizer of the Fazlur R. Khan Distinguished Lecture Series (http://www.lehigh.edu/frkseries) at Lehigh University. He is an experienced researcher and consultant to industry and government agencies, both nationally and abroad. His main research interests are in the application of probabilistic concepts and methods to civil and marine engineering, including structural reliability, probabilitybased design and optimization of buildings, bridges and naval ships, structural health 
monitoring, life-cycle performance maintenance and management of structures and infrastructures under uncertainty, risk-based assessment and decision making, infrastructure sustainability and resilience to disasters, stochastic mechanics and earthquake engineering.

According to ASCE (2010) "Dan M. Frangopol is a preeminent authority in bridge safety and maintenance management, structural systems reliability, and life-cycle civil engineering. His contributions have defined much of the practice around design specifications, management methods, and optimization approaches. From the maintenance of deteriorated structures and the development of system redundancy factors to assessing the performance of long-span structures, Dr. Frangopol's research has not only saved time and money, but very likely also saved lives."

Dr. Frangopol's work has been funded by NSF, FHWA, NASA, ONR, WES, AFOSR, ARDEC and by numerous other agencies. He is the Founding President of the International Association for Bridge Maintenance and Safety (IABMAS, www.iabmas.org) and of the International Association for Life-Cycle Civil Engineering (IALCCE, www.ialcce.org), and Past Director of the Consortium on Advanced Life-Cycle Engineering for Sustainable Civil Environments (COALESCE). He is also the Vice-President of the International Association for Structural Safety and Reliability (IASSAR, www.columbia.edu/cu/civileng/iassar), the former Vice-President of the International Society for Health Monitoring of Intelligent Infrastructures (ISHMII, www.ishmii.org), and the founder and current chair of the ASCE Technical Council on Life-Cycle Performance, Safety, Reliability and Risk of Structural Systems (http://content.seinstitute.org/committees/strucsafety.html).

Dr. Frangopol is the recipient of several prestigious awards including the 2014 ASCE James R. Croes Medal, the 2012 IALCCE Fazlur R. Khan Life-Cycle Civil Engineering Medal, the 2012 ASCE Arthur M. Wellington Prize, the 2012 IABMAS Senior Research Prize, the 2008 IALCCE Senior Award, the 2007 ASCE Ernest Howard Award, the 2006 IABSE OPAC Award, the 2006 Elsevier Munro Prize, the 2006 T. Y. Lin Medal, the 2005 ASCE Nathan M. Newmark Medal, the 2004 Kajima Research Award, the 2003 ASCE Moisseiff Award, the 2002 JSPS Fellowship Award for Research in Japan, the 2001 ASCE J. James R. Croes Medal, the 2001 IASSAR Research Prize, the 1998 and 2004 ASCE State-of-the-Art of Civil Engineering Award, and the 1996 Distinguished Probabilistic Methods Educator Award of the Society of Automotive Engineers (SAE). Among several awards he has received at the University of Colorado, Frangopol is the recipient of the 2004 Boulder Faculty Assembly Excellence in Research Scholarly and Creative Work Award, the 1999 College of Engineering and Applied Science's Research Award, the 2003 Clarence L. Eckel Faculty Prize for Excellence, and the 1987 Teaching Award. He is also the recipient of the Lehigh University's 2013 Eleanor and Joseph F. Libsch Research Award. He has given plenary keynote lectures in numerous major conferences held in Asia, Australia, Europe, North America, South America, and Africa.

Dr. Frangopol is the Founding Editor-in-Chief of Structure and Infrastructure Engineering (Taylor \& Francis, www.informaworld.com/sie), an international peer reviewed journal. This journal is dedicated to recent advances in maintenance, management, and life-cycle performance of a wide range of structures and infrastructures. $\mathrm{He}$ is the author or co-author of two books, 38 book chapters, more than 300 articles in referred journals, and over 500 papers in conference proceedings. He is also the 
editor or co-editor of 40 books published by ASCE, Balkema, CIMNE, CRC Press, Elsevier, McGraw-Hill, Taylor \& Francis, and Thomas Telford, and an editorial board member of several international journals. Additionally, he has chaired and organized several national and international structural engineering conferences and workshops.

Dr. Frangopol has supervised 37 Ph.D. and 54 M.Sc. students. Many of his former students are professors at major universities in the United States, Asia, Europe, and South America, and several are prominent in professional practice and research laboratories.

For additional information on Dr. Frangopol's activities, please visit http://www.lehigh.edu/ dmf206/ 


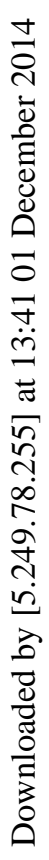




\section{Preface}

The purpose of this book is to present the latest research findings in the field of maintenance and safety of aging infrastructure. For this purpose, the aim was to attract state-of-the-art papers that deal with the use of advanced computational and/or experimental techniques in damage and vulnerability assessment as well as maintenance and retrofitting of aging structures and infrastructures (e.g., buildings, bridges, lifelines, and naval ships). A deteriorating infrastructure leads to increased functioning costs and reduced safety and can lead to a catastrophic failure with devastating environmental, social and economic consequences. In contrast, well-maintained civil infrastructure can substantially increase a country's competitiveness in a global economy and enhance resilience to adverse circumstances such as natural hazards (e.g., earthquakes, hurricanes and floods) and man-made disasters (e.g., vehicular collision and blasts due to terrorists' attacks).

Cost-efficient maintenance and management of civil infrastructure systems requires balanced consideration of both the system performance and the total cost accrued over their entire life-cycle. Another major problem is that the performance of structural systems is usually reduced during its functioning due to aging, environmental stressors, and other factors. Thus, current structural condition state is usually assessed by visual inspection or more advanced automatic structural health monitoring techniques. Furthermore, maintenance managers often require a list of prioritized maintenance interventions for civil infrastructure on an annual and/or long-term basis. Various unavoidable uncertainties associated with both randomness (i.e., aleatory uncertainty) and imperfect knowledge (i.e., epistemic uncertainty) also play a crucial role in maintenance and management of engineering systems. Taking into account the aforementioned issues, this volume aims to present the recent developments of life-cycle maintenance and management planning for deteriorating civil infrastructure considering simultaneously the present thinking as well as the latest research findings in this area. This volume is a book of high-quality and self-contained chapters, which present the state-of-the-art theoretical advances and applications in various areas of maintenance and safety of aging infrastructure. This edited book consists of selected contributions of experts in the aforementioned field.

In this context, major topics treated in this book include: risk assessment, redundancy, robustness, management, safety, reliability, optimization, structural health monitoring, life-cycle performance, extreme events, hazards, dynamic assessment, retrofitting, bridge networks, fatigue life, stochastic control, decision making, bridges, marine structures, dams, pavements, aging structures, uncertainties, NDT methods, 
damage assessment, climate change, climate adaptation, sustainability, hazard mitigation, inspection, maintenance and repair, as briefly described below. Due to the multidisciplinary nature and complexity of the topics and the applications covered in the chapters of this volume they are not categorized, but instead they are placed in alphabetic order (based on first author's last name).

In the first chapter, M. Akiyama, D.M. Frangopol and H. Matsuzaki present fundamental issues related to reliability-based durability and service life assessment of reinforced concrete $(\mathrm{RC})$ structures in a marine environment, where a major problem is the chloride-induced corrosion of reinforcing bars. As it is explained for new RC structures, the concrete quality and concrete cover to prevent the chloride-induced reinforcement corrosion causing the deterioration of structural performance during whole lifetime of RC structures should be determined. For this purpose, a simple design criterion with durability design factors that satisfy the target reliability level is presented. On the other hand, for evaluating the service life of existing structures, it is necessary to consider the effect of the chloride-induced reinforcement corrosion on the deterioration of structural capacity and stiffness. Hence, to evaluate the capacity and stiffness of deteriorated structures, spatial variability associated with the steel weight loss over the entire components needs to be considered using X-ray photography and digital image processing. It is concluded that based on service life reliability assessment of existing RC structures by incorporating spatial variations, the optimal temporal and spatial intervals of inspection could be determined.

S. Alampalli advocates that bridge inspections and maintenance are essential to assure safety, increase durability, reduce life-cycle costs, maintain mobility, and improve reliability of transportation networks. The chapter focuses on bridges in the United States, which are usually examined using visual methods by bridge inspectors, manually assessing the condition of various elements. These inspections form a basis for maintenance and other repair actions that are needed to improve durability and maintain the required service level. Therefore, inspection and maintenance issues should be considered by engineers to ensure that all components can be accessed and evaluated by inspection and maintenance personnel, so that appropriate maintenance and repairs can be performed in a cost-effective and timely fashion. This will assure long-term durability, while not significantly affecting the level of service and mobility. These issues are presented herein based on the established practice, experience, norms and guidelines among bridge designers and inspectors as well as maintenance engineers in the United States.

The chapter by A. Alipour and B. Shafei deals with structural vulnerability measures for the assessment of deteriorating bridges in seismic prone areas. For this purpose, the authors propose a vulnerability index as a time-dependent measure of the seismic damageability of deteriorating bridges. To estimate this index, the life-cycle performance of reinforced concrete highway bridges subjected to earthquake ground motions is evaluated under the assumption that the bridge components are continuously exposed to the attack of chloride ions. Corrosion process of the concrete is simulated through a computational approach that calculates structural degradation over the entire service life of the structural components. The structural capacity and seismic response of corroded bridges is investigated and seismic fragility curves are generated for the deteriorating bridges using updated parameters. The time-dependent fragility curves are employed to predict the vulnerability index, which combines the effects of expected 
seismic events and chloride-induced corrosion. This index can be used for the structural design and performance assessment of bridges as well as for the life-cycle cost analysis of bridges subjected to multiple natural hazards and environmental stressors.

The design of complex structural systems requires an accurate definition of the project requirements and a detailed verification of the expected performance. Structural condition knowledge that can be gained by structural health monitoring is the topic of the contribution by S. Arangio and F. Bontempi. In this context, it is stressed that structural health monitoring (SHM) plays an essential role to improve the knowledge level for a complex structural system and to allow reliable evaluations of the structural safety in operational conditions. SHM should be planned from the design phase and carried out during the entire life-cycle, since it represents an effective way to control the structural system in a proactive way. By using SHM the circumstances that may eventually lead to deterioration, damage and unsafe operations can be diagnosed and mitigated in a timely manner, thus, costly replacements can be avoided or delayed. In order to deal with the large quantity of data gathered from the continuous monitoring various techniques exist. In this work, different approaches are discussed and applied to illustrate how SHM can lead to two levels of design knowledge gain: locally, on the specific structure, and more globally, on the general class of similar structures.

Safety analysis and maintenance scheduling of critical infrastructure become increasingly complicated due to uncertainties and complexity, which result significantly from aging and from interactive phenomena. In the chapter by M. Beer, I.A. Kougioumtzoglou and E. Patelli established and emerging concepts and techniques for efficient and realistic uncertainty quantification are discussed. In this regard, emphasis was put on engineering applications, and in particular, on challenges associated with civil engineering structures and infrastructure to verify and ensure their safety. For this purpose, the main two challenges discussed are: (a) the realistic and reliable quantification of uncertainties prevalent in civil engineering complex systems, and (b) the efficient numerical analysis of such complex systems in the presence of uncertainties. Emerging concepts and approaches which address these challenges are presented.

The aim of the chapter by F. Biondini and D.M. Frangopol is to present the latest research findings in the field of structural robustness and progressive collapse of deteriorating structural systems, with emphasis on the relationship among structural robustness, static indeterminacy, structural redundancy, and failure times. Damage is viewed as a progressive deterioration of the material properties and its amount is evaluated at the member level by means of a damage index associated with prescribed patterns of cross-sectional deterioration. An index of structural integrity is also defined to quantify the severity of the structural failure with respect to its consequences. The role of damage propagation on structural robustness is investigated by considering different propagation mechanisms and by using a damage-sensitive fault-tree analysis. The elapsed time between local failure and structural collapse is also investigated as an indicator of the ability of the system to be repaired after local failure. The methodology is implemented on a reinforced concrete frame under different corrosion damage scenarios.

E. Brühwiler introduces a novel approach to verify the fatigue safety of existing bridges using monitored data in an explicit way and to predict their future service life. A methodology to exploit data from long-term monitoring for gaining meaningful information is presented. The approach is illustrated by its application to real 
bridges in Switzerland. It is shown that there are no 'old' bridges, but bridges that provide adequate performance or not. Therefore, extending the service life of bridges by following the approach presented herein allows for continuous utilization of existing structures rather than their replacement which introduces a novel meaning to the notion of "lifecycle" of civil structures. Hence, this approach is clearly in agreement with the principles of sustainable development.

Management and safety of existing concrete structures via optical fiber distributed sensing is investigated by J.R. Casas, S. Villalba and V. Villalba. More specifically, the use of Optical Backscatter Reflectometer (OBR) as a distributed fiber optic system to measure strain and detect cracking in concrete structures is examined. A laboratory test as well as two real structures (a bridge and a cooling tower of a power plant) were used to investigate the effectiveness of the OBR sensors when applied to complex and large-scale structural systems. The presented results show the feasibility of this technique despite of the roughness of the concrete surface and the heterogeneity due to the presence of aggregates of different sizes. All applications verify that OBR sensors are capable of detecting cracks that are hardly visible. Crucial factors are the good preparation of the concrete surface as well as the adoption of the correct bonding agent, while extra care is necessary whenever continuous fiber has curvature changes. Regarding cost, it is pointed out that the deployment of the OBR monitoring system in real-world infrastructure is more economical compared to equivalent monitoring techniques.

The chapter by Á. Cunha, E. Caetano, F. Magalhães and C. Moutinho describes in a concise and systematic manner the most important issues related to the dynamic testing and continuous monitoring of large-scale civil infrastructure. For this purpose, an extensive discussion of modern perspectives concerning testing techniques, instrumentation, modal identification, vibration serviceability safety checking and damage detection is presented. Special attention is given on the efficient implementation of Operational Modal Analysis (OMA) and its application for tracking the evolution of modal parameters in long-term dynamic monitoring applications. In addition, it is also illustrated that statistical methods can be used to remove the influence of environmental and operational factors (e.g., temperature, intensity of traffic, wind) on the modal variability, supporting the development of reliable techniques for vibration based damage detection. Moreover, it is demonstrated that continuous dynamic monitoring can also be used for safety checking of vibration serviceability limits as well as for better understanding wind induced effects on the modal properties or the structural response of large-scale structures.

D. De Leon-Escobedo, D.J. Delgado-Hernandez and J.C. Arteaga-Arcos advocate in their contribution that the balanced implementation of strategies to design and maintain facilities must consider the risk management as a tool to measure the economical effectiveness of alternatives and to allocate limited resources effectively. Under this perspective, the approaches presented are based on the expected life-cycle cost analysis and Bayesian networks, the first of which is applied to the case of a bridge and an offshore oil platform, and the latter to an earth dam in Mexico. The impact of cost/benefit ratios, epistemic uncertainties and the relative importance of contributing factors are weighted and used as a decision making tool for a risk-based planning of resources allocation for maintenance of structures with different revenues/cost ratios. 
Risk-based maintenance of aging ship structures is the focus of the study by Y. Garbatov and C. Guedes Soares. Their chapter reviews recently developed mathematical tools for risk-based assessment of marine structures subjected to the degrading effect of corrosion. It discusses the methods for corrosion deterioration modeling and presents a formulation for the reliability assessment and risk-based maintenance planning of corroded marine structures taking into account different maintenance strategies. Furthermore, it is noted that inspection planning reveals that the application of repair cost optimization for floating structures involves many uncertainties. Classical theory of system maintenance that describes the failure of components by Weibull probabilistic models, which represent failure rates in operational phases and in the aging phases of the life of components are used.

As illustrated in the work of K. Kaito, K. Kobayashi and K. Obama, the deterioration of pavement is a complex phenomenon in which the deterioration process of road surface and the decline in load bearing capacity of the entire pavement occur concurrently. In pavement management, it is important to comprehensively assess the deterioration state of the pavement structure and determine desirable repair policies. In this study, the authors propose a methodology for discussing a pavement repair policy for a target road span by (a) extracting intensive management spans through the relative evaluation of road surfaces based on the results of road condition surveys, and (ii) estimating the load bearing capacity through the falling weight deflectometer (FWD) survey targeted at intensive management spans. For this purpose, the mixed Markov deterioration hazard model is applied to national road in Japan, and intensive management spans are selected by comparing heterogeneity parameters. A FWD survey is conducted and load bearing capacity is measured for the selected intensive management spans and some of sound road spans, and the authors empirically verify the appropriateness of the proposed method of extracting intensive management spans through the comparison of heterogeneity parameters.

S. Lavrenz, J. Murillo Hoyos and S. Labi illustrate the importance of assessing the effectiveness of alternative infrastructure preservation interventions, typically, in terms of a measure of effectiveness (MOE) which is in turn expressed in the form of a performance indicator (PI). It is important to perform such quantifications as part of ex post evaluations (i.e., after the intervention) or in ex ante assessments of infrastructure intervention projects (i.e., before the decision is made either to proceed with an intervention or to identify the optimal choice from multiple alternative interventions). This would facilitate the development of explicit, objective, and consistent decisions based on all relevant and quantifiable cost or benefits associated with the intervention. For this purpose, this chapter presents MOEs that include increase in performance (the extent to which the performance indicator (PI) is enhanced over the remaining life of the infrastructure), the service life (the time or accumulated loadings for the PI to reach a pre-specified threshold), and the area bounded by the performance function (a reflection of the time period over which good performance is sustained, representing both the average performance and the intervention service life), probability of infrastructure survival until a certain time, and the probability that some distress of a certain extent or severity is encountered. Field data from in-service infrastructure are used to demonstrate the use of these mathematical constructs.

The chapter by Y. Li, M.G. Stewart and S. Bjarnadottir presents a risk-based framework to assess the hurricane damage risks of power distribution (utility) poles, 
investigate the cost-effectiveness of different mitigation strategies, and evaluate adaptation strategies under potential climate change. The losses due to power outrage and the high replacement costs of aging poles requires a detailed investigation into the cost effectiveness of various mitigation strategies, which may reduce replacement costs and damage risks. The framework includes a reliability analysis of the power distribution poles using fragility analysis considering various sources of uncertainties, the effects of degradation of timber poles, probabilistic wind models, a life-cycle cost (LCC) benefit analysis for economical viability of various mitigation strategies, and an assessment of the potential impacts of climate change on annual failure probability of power distribution poles. Climate change is found to have a significant impact on the annual failure probability of the distribution poles when they are subjected to changing patterns of hurricane hazard. Under this perspective, the economic viability of adaptation strategies to replace or strengthen power distribution poles in coastal areas under various climate change scenarios is evaluated.

As it is explained in the contribution of A. Medury and S. Madanat, transportation infrastructure management refers to the process of allocating a limited set of resources to a system of deteriorating facilities (roads, bridges, tunnels, etc) for maintenance, rehabilitation and replacement (MR\&R) activities. Typically, the objective is to minimize the total costs incurred by the agency over a given planning horizon, while providing adequate recognition to the performance of individual facilities, as well as the costs incurred by the users. In order to model the decision-making problem, which involves the optimization of decisions over multiple stages, Markov decision processes (MDP) are widely used, especially in the context of incorporating uncertainty in the underlying facility performance models. In this regard, state-of-the-art Markov decision process (MDP)-based approaches in infrastructure management are presented. Furthermore, this work seeks to explore the suitability of approximate dynamic programming (ADP) methods to incorporate network-induced dynamics into system-level MR\&R decision-making. An efficient ADP framework is proposed to incorporate structural and economic interdependence into network-level MR\&R decision-making, while parametric studies are conducted to infer the impact of network-based constraints on the decision-making process.

The impact of corrosion into the safety of structures in marine environments is the objective of the chapter by R.E. Melchers. More specifically, corrosion and pitting of structural steel used in marine pipelines and for off-shore mooring chain are important factors in continued integrity and service performance and are best considered in a reliability framework. Recent new studies have shown that corrosion and pitting are complex nonlinear functions of exposure period and of various environmental influences, including that of marine microorganisms. This has considerable implications on the way structural safety assessments using structural reliability theory can be performed. This aspect is reviewed for steel plates, sheet piling, steel pipelines and for mooring chains as used in the offshore oil industry. An example is given for the assessment of the probability of failure through severe pitting observed in some cases for mooring chains. The new corrosion theory implies that for maximum pit depth the Frechet distribution rather than the usual Gumbel distribution is more appropriate for reliability analysis. The reasons for this outcome and the various implications are discussed. 
Important techno-economic issues related to reliable and efficient retrofitting and refurbishment of existing road bridges are discussed by C. Modena, G. Tecchio, C. Pellegrino, F. da Porto, M.A. Zanini and M. Donà. It is evident that suitable interventions are essential for lengthening bridges' structural life and delaying their complete substitution, the "downtime" costs, all generally very difficult to manage by network authorities. The design of retrofit process requires a complex comprehensive approach, which starts with the assessment of the current state and the definition of the condition value of the bridge by inspections, identification tests, structural analyses, etc. On this basis, the definition of the proper interventions in terms of both material and implementation techniques is then carried out. The application of such methodologies to different road bridge types (masonry, reinforced concrete, steel) is described, while usual restoration and retrofitting techniques for all these different bridge types are briefly presented. In the sequence, significant case studies of rehabilitation interventions are presented. These retrofitting and refurbishment interventions outline a methodological approach, taking into account the typological characteristics of the structure, the state of maintenance, the functional requirements and the environmental aspects connected to the employed repair and strengthening of each structural system.

K.G. Papakonstantinou and M. Shinozuka discuss stochastic control approaches for structural maintenance. In general, huge investments are needed in order to substantially improve the current infrastructure conditions, which are rarely, if ever, fully available in practice. To address effectively this urgent societal need for safe structures and infrastructure systems under limited resources, science-based management of assets is needed. Stochastic control methods and Bayesian principles have a long, successful history of implementation in risk management and minimum life-cycle costing of civil engineering structures. In this work, a practical framework for decision-making, under a variety of uncertainties, concerning the management of deteriorating civil structures is presented based on Markov Decision Processes (MDP) that answers the critical questions of where, when and what type of inspection and repair should be performed, in order for a structure to maintain an acceptable safety level at the minimum possible cost. This enables decision-makers to plan an optimum life-cycle policy to perform effective inspection and maintenance actions. Utilizing a realistic example, the proposed method is compared with state-of-the-art methodologies to verify its theoretical and practical supremacy.

Modeling inspection uncertainties for on-site condition assessment using nondestructive testing (NDT) tools is discussed in the work of F. Schoefs. Maintenance of existing aging infrastructures lies generally on condition assessment based-from the most easily used to the most intrusive ones- on visual inspection, non-NDT and structural health monitoring (SHM) with embedded sensors. For some applications, the condition assessment can be considered as perfect and the aging model parameters are updated using Bayesian techniques for instance. When considering aging infrastructures this is generally not the case due to: (a) the size of the structure is large and the inspection should be carried out on a limited number of positions; (b) the budget devoted to inspection is subtracted from the global amount of money available to plan the Inspection-Maintenance and Repair schedule (IMR). Thus, the most efficient and inexpensive condition assessment schemes should be selected. That leads decisionmakers to consider: (i) partial, and (ii) non-perfect tools in the decision scheme. The objective of this chapter related to (i) is: to present deficiencies of classical discrete 
inspection approaches, to describe the current methodologies for inspection optimisation, and to present an efficient approach based on polynomial chaos to minimize the error of measurement. Furthermore, the goals of this chapter with respect to (ii) are: to present in a general format the modelling of imperfections, emphasizing on the role of the exact definition of the employed protocol, as well as the chain of uncertainties from calibration tests and results in laboratory to on-site assessment including various factors (i.e., human, environmental,) that affect the assessment. Furthermore, to analyse how these basic quantities can be introduced as parameters in a rational aid-tool for the optimisation of resources allocation by minimizing the total cost along the service life.

The motivation of the study by M.-K. Söderqvist is to examine the impact of condition description and inspection data quality in infrastructure management. It is emphasized that a well-organized inspection system is the key element of a successful engineering structure management. Actually, it forms the basis and is an integral part of the whole management system. The system assessment results are as reliable as the data in the database. Hence, the experience of the engineers and the use of the management system have shown that the available condition and damage data must continuously be improved and completed. The importance of inspection training and other quality improving methods, their impact on bridge maintenance, repair and rehabilitation (MR\&R) as well as bridge aging modeling are discussed. MR\&R preservation and functionality goals for bridges and other engineering structures are presented to better describe the whole management process of fund allocation. Well qualified inspection and well-chosen condition indicators provide a valuable and necessary assistance to reach the targets of the maintenance operations policy.

The topic of the contribution of M.G. Stewart, D.V. Val, E. Bastidas-Arteaga, A. O'Connor and X. Wang climate adaptation engineering and risk-based design and management of infrastructure, with emphasis on increases in economic (loss) risks expected for existing infrastructure subject to climate-induced changes. This work aims at exploiting the impact of climate change on infrastructure performance and to pave the way for more efficient and resilient infrastructure, and help 'future proof' existing infrastructure to a changing climate. The performance of existing infrastructure may degrade if subject to more extreme natural hazards or accelerated degradation of material properties. This chapter describes how risk-based approaches are well suited to optimising climate adaptation strategies related to the design and maintenance of existing infrastructure. Such approaches may include retrofitting or strengthening of existing structures, or enhanced designs. Risk-based decision support is described to assess the risks and economic viability of climate adaptation measures, especially on the aspect of life-cycle costs during their service, which includes embodied and operating energy costs. Furthermore, stochastic methods are used to model infrastructure performance, effectiveness of adaptation strategies, exposure, and costs. The latest research findings related to climate adaptation strategies are provided for various complex engineering applications.

Large-scale transportation networks comprise structures of various size and complexity, requiring different strategies for management and maintenance. Under this perspective, the work of B. Yanev focuses on comparing bridge condition evaluations with life-cycle expenditures in an illustrative manner. More specifically, the objective of this chapter is to review the condition assessments of the New York City bridge 
network and the known expenditures for rehabilitation, repair and maintenance over a period exceeding two decades. The evaluations include condition ratings generated by visual biennial inspections, as well as reports of potential hazards and other assessments. In contrast with uncertain forecasting models, this work directly compares the bridge condition database with the magnitude of the remedial measures. Given the uncertain correlation between evaluations and actual conditions on one hand, and the vague effectiveness of remedial actions on the other, a rigorous relationship cannot be established even in retrospect. Nevertheless, comparing a huge amount of real data from bridge and element condition ratings with network level expenditures reveals a functional relationship between the project level structural demand and the supply of remedial actions. Hence, important guidelines are provided based on the accumulated experience of the presented bridge network and it is concluded that preventive maintenance and preservation emerge as preferable, both in terms of direct and user costs, especially for larger infrastructure.

In the last chapter, the principles of redundancy-based design of non-deterministic systems are presented by B. Zhu and D.M. Frangopol. The motivation of this study is to propose an efficient redundancy factor to provide a rational reliability-based design of components in structural systems. The definition of this redundancy factor is properly illustrated via a characteristic example. By using idealized systems consisting of identical components, the effects of system models, correlations among the resistances of components, number of components in the system, mean value of the load, and coefficients of variation of load and resistances on the redundancy factor are investigated. For the representative case where the coefficients of variation of resistance and load are set to be the commonly used values, the redundancy factors of $\mathrm{N}$-component systems associated with different correlation cases and system models are evaluated. Two types of limit states are provided, in which system redundancy is taken into account from the load and resistance side, respectively. Finally, a highway bridge example is presented to demonstrate the application of the proposed redundancy factor to real-life engineering problems.

The aforementioned collection of chapters provides an overview of the present thinking and state-of-the-art developments into the field of maintenance and safety of aging infrastructure. The book is targeted primarily to researchers, students and engineers that are active in this field. It is hoped that the collection of these chapters in a single book will be found useful for both academics and practicing engineers.

The book editors would like to express their deep gratitude to all authors for their time and effort devoted to the completion of their contributions for this volume. Furthermore, we are most appreciative to the reviewers for their effective comments that helped authors to substantially strengthen their work. Finally, the editors would like to thank the personnel of CRC Press / Balkema, especially Mr. Alistair Bright and Mr. Richard Gundel, for their kind cooperation and support for the publication of this book.

\section{Dan M. Frangopol}

Yiannis Tsompanakis

September 2014 


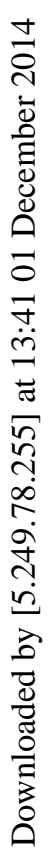




\section{About the Editors}

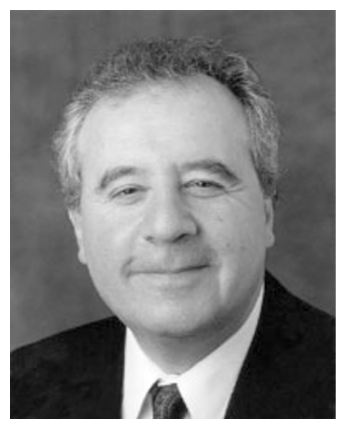

Dr. Dan M. Frangopol is the first holder of the Fazlur R. Khan Endowed Chair of Structural Engineering and Architecture at Lehigh University. Before joining Lehigh University in 2006, he was Professor of Civil Engineering at the University of Colorado at Boulder, where he is now Professor Emeritus. From 1979 to 1983, he held the position of Project Structural Engineer with A. Lipski Consulting Engineers in Brussels, Belgium. In 1976, he received his doctorate in Applied Sciences from the University of Liège, Belgium. In 2010, ASCE named him a Distinguished Member for defining much of the practice for life-cycle management methods of deteriorating structures and optimization approaches, and noted that his work has "not only saved time and money, but very likely also saved lives."

Dr. Frangopol is an experienced researcher and consultant to industry and government agencies, both nationally and abroad. His work has been funded by NSF, FHWA, ONR, NASA, WES, AFOSR, ARDEC and by numerous other agencies.

Dr. Frangopol holds three honorary doctorates from Belgium and Romania. $\mathrm{He}$ is an Honorary Professor at seven universities (Hong Kong Polytechnic, Tongji, Southeast, Tianjin, Chang'an, Dalian, and Harbin Institute of Technology). For his contributions, Dr. Frangopol has been recognized with several prestigious awards, including the T. Y. Lin Medal, Newmark Medal, Khan Life-Cycle Civil Engineering Medal, Croes Medal (twice), Howard Award, Wellington Prize and Moisseiff Award, to name only a few.

Dr. Frangopol is devoted to serving the profession, having held various leadership positions in national and international organizations. He is the Founding President of the International Association for Bridge Maintenance and Safety (IABMAS) and of the International Association for Life Cycle Civil Engineering (IALCCE), and the Vice-President of the International Association for the Structural Safety and Reliability (IASSAR). He is also the Founding Chair of the ASCE-SEI Technical Council on life-cycle performance, safety, reliability and risk of structural systems and of the IASSAR Technical Committee on life-cycle performance, cost and optimization. He is a member of the Board of Governors of the Engineering Mechanics Institute (EMI) of the ASCE, Past-Chair of the Technical Activities Division of the 20,000+ members of the Structural Engineering Institute (SEI) of the ASCE, and Past Vice-President of the International Society for Structural Health Monitoring of Intelligent Infrastructure 
(ISHMII). He is also Honorary President of both the IABMAS-Italy Group and the IABMAS-Brazil Group, and Honorary Member of the IABMAS-Portugal Group and IABMAS-China Group.

Dr. Frangopol has left an indelible legacy of work, having authored or co-authored more than 350 books, book chapters, and refereed journal articles, and numerous papers in conference proceedings. He is the founding Editor-in-Chief of Structure and Infrastructure Engineering, a peer-reviewed journal.

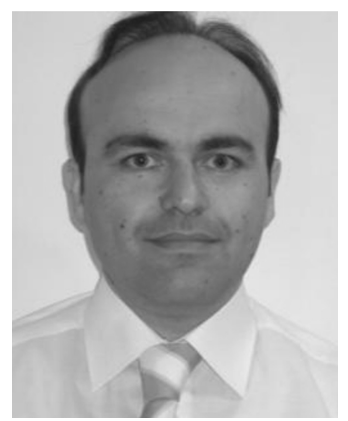

Dr. Yiannis Tsompanakis is a civil engineer specialized in computational dynamic methods in engineering. He is Associate Professor in the School of Environmental Engineering of the Technical University of Crete, Greece and Head of Computational Dynamics Research Group. He teaches several undergraduate \& postgraduate courses structural and computational mechanics as well as earthquake engineering and has supervised $\mathrm{PhD}, \mathrm{MSc}$ and Diploma theses. He is expert in development and application of advanced simulation techniques and computational methods for dynamic analysis of structures and infrastructure. His research and engineering interests and expertise include structural and geotechnical earthquake engineering, geoenvironmental engineering, soil-structure interaction, structural optimization, probabilistic mechanics, structural integrity assessment $\&$ monitoring, life-cycle analysis $\&$ performance-based design, and artificial intelligence methods, among others.

As an internationally recognized researcher he has published more than 150 publications (journal papers, international conference papers, book chapters, edited volumes and conference proceedings). He has also prepared special issues in journals and organized several conferences, special sessions and mini-symposia and has also presented invited lectures in international conferences. He is the organizer of the International Conference Series on Soft Computing Technology in Civil, Structural and Environmental Engineering and the editor of the resulting proceedings and invited papers volumes. He is reviewer for many archival scientific engineering journals and member of the editorial member in several international journals. He has been a scientific board member in many conferences. Furthermore, he is the Technical Editor of Structure and Infrastructure Engineering Journal (Taylor \& Francis Publ.). He is member of many international scientific organizations and associations and he is the Secretary of International Association for Structural Safety and Reliability (IASSAR) TC4 Technical Committee: Life-cycle performance, cost and optimization.

Dr. Tsompanakis has excellent leadership, interpersonal and negotiating skills and many international cooperations with other scientific groups and engineering firms in Greece and abroad (USA, UK, Italy, Germany, France, Serbia, Spain, etc.). He is highly skilled in implementation and management of quantitative/qualitative state-of-the-art research. He has significant practical and scientific experience from his participation in many national and international projects (structures, geostructures, lifelines, etc.), working either with his group or jointly with other collaborating teams. He has also served in many administrative positions at the Technical University of Crete. 


\section{Contributors List}

Akiyama, M., Department of Civil and Environmental Engineering, Waseda University, Tokyo, Japan

Alampalli, S., New York State Department of Transportation, Albany, New York, USA Alipour, A., Department of Civil and Environmental Engineering, University of Massachusetts, Amberst, Massachusetts, USA

Arangio, S., Department of Structural and Geotechnical Engineering, Sapienza University of Rome, Rome, Italy

Arteaga-Arcos, J.C., Civil Engineering Department, School of Engineering, Universidad Autónoma del Estado de México, Toluca, Mexico

Bastidas-Arteaga, E., Institute for Civil and Mechanical Engineering Research, University of Nantes, Nantes, France

Beer, M., Institute for Risk \& Uncertainty, University of Liverpool, Liverpool, UK

Biondini, F. Department of Civil and Environmental Engineering, Politecnico di Milano, Milan, Italy

Bjarnadottir, S., College of Engineering, Technology and Architecture, University of Hartford, West Hartford, Connecticut, USA

Bontempi, F., Department of Structural and Geotechnical Engineering, Sapienza University of Rome, Rome, Italy

Brühwiler, E., Civil Engineering Institute, Swiss Federal Institute of Technology, Lausanne, Switzerland

Caetano, E., Faculty of Engineering, University of Porto, Porto, Portugal

Casas, J.R., Construction Engineering Department, Technical University of Catalonia, Barcelona, Spain

Cunha, Á., Faculty of Engineering, University of Porto, Porto, Portugal

da Porto, F., Department of Civil, Environmental and Architectural Engineering, University of Padova, Padova, Italy

De Leon Escobedo, D., Civil Engineering Department, School of Engineering, Universidad Autónoma del Estado de México, Toluca, Mexico

Delgado-Hernandez, D.J., Civil Engineering Department, School of Engineering, Universidad Autónoma del Estado de México, Toluca, Mexico

Donà, M., Department of Civil, Environmental and Architectural Engineering, University of Padova, Padova, Italy

Frangopol, D.M., Department of Civil and Environmental Engineering, Lehigh University, Bethlehem, Pennsylvania, USA 
Garbatov, Y., Centre for Marine Technology and Engineering, Instituto Superior Técnico, University of Lisbon, Lisbon, Portugal

Guedes Soares, C., Centre for Marine Technology and Engineering, Instituto Superior Técnico, University of Lisbon, Lisbon, Portugal

Kaito, K., Graduate School of Engineering, Osaka University, Osaka, Japan

Kobayashi, K., Graduate School of Management, Kyoto University, Kyoto, Japan

Kougioumtzoglou, I.A., Institute for Risk \& Uncertainty, University of Liverpool, Liverpool, UK

Labi, S., School of Civil Engineering, Purdue University, West Lafayette, Indiana, USA Lavrenz, S., School of Civil Engineering, Purdue University, West Lafayette, Indiana, USA

Li, Y., Department of Civil and Environmental Engineering, Michigan Technological University, Houghton, Michigan, USA

Madanat, S., Department of Civil and Environmental Engineering, University of California Berkeley, California, USA

Magalhães, F., Faculty of Engineering, University of Porto, Porto, Portugal

Matsuzaki, H., Department of Civil and Environmental Engineering, Tohoku University, Sendai, Japan

Medury, A., Safe Transportation Research and Education Center, University of California Berkeley, California, USA

Melchers, R.E., Centre for Infrastructure Performance and Reliability, The University of Newcastle, Newcastle, Australia

Modena, C., Department of Civil, Environmental and Architectural Engineering, University of Padova, Padova, Italy

Moutinho, C., Faculty of Engineering, University of Porto, Porto, Portugal

Murillo Hoyos, J., School of Civil Engineering, Purdue University, West Lafayette, Indiana, USA

O’Connor, A., Department of Civil, Structural \& Environmental Engineering, Trinity College, Dublin, Ireland

Obama, K., Graduate School of Engineering, Osaka University, Osaka, Japan

Papakonstantinou, K.G., Department of Civil Engineering and Engineering Mechanics, Columbia University, New York City, New York, USA

Patelli, E., Institute for Risk \& Uncertainty, University of Liverpool, Liverpool, UK

Pellegrino, C., Department of Civil, Environmental and Architectural Engineering, University of Padova, Padova, Italy

Schoefs, F., Institute for Civil and Mechanical Engineering Research, University of Nantes, Nantes, France

Shafei, B., Department of Civil and Environmental Engineering, University of Massachusetts, Amberst, Massachusetts, USA

Shinozuka, M., Department of Civil Engineering and Engineering Mechanics, Columbia University, New York City, New York, USA

Söderqvist, M.-K., Finnish Transport Agency, Helsinki, Finland

Stewart, M.G., Centre for Infrastructure Performance and Reliability, The University of Newcastle, Newcastle, Australia

Tecchio, G., Department of Civil, Environmental and Architectural Engineering, University of Padova, Padova, Italy 
Val, D.V., Institute for Infrastructure and Environment, Heriot-Watt University, Edinburgh, UK

Villalba, S., Construction Engineering Department, Technical University of Catalonia, Barcelona, Spain \& CRACK Ingenieria Catalana - COTCA S.A. Partners, Barcelona, Spain

Villalba, V., Construction Engineering Department, Technical University of Catalonia, Barcelona, Spain \& SGS Tecnos S.A., Barcelona, Spain

Wang, X., CSIRO Climate Adaptation Flagship and CSIRO Ecosystem Sciences, Commonwealth Science and Industrial Research Organisation, Clayton, South Highett, Victoria, Australia

Yanev, B., Department of Transportation, New York City, New York, USA

Zanini, M.A., Department of Civil, Environmental and Architectural Engineering, University of Padova, Padova, Italy

Zhu, B., Department of Civil and Environmental Engineering, Lehigh University, Bethlehem, Pennsylvania, USA 


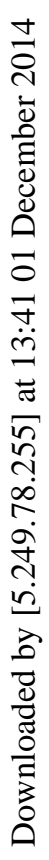




\title{
Author Data
}

\author{
Akiyama, Mitsuyoshi \\ Department of Civil and Environmental Engineering \\ Waseda University \\ 3-8 Okubo, Shinjuku-Ku \\ Tokyo 169-855, Japan \\ Tel: +81-3-5286-2694 \\ Email: akiyama617@waseda.jp
}

Alampalli, Sreenivas

Structures Evaluation Services Bureau

New York State Department of Transportation

Albany, NY, 12232, USA

Tel: +1-518-457-5498

Email: Sreenivas.Alampalli@dot.ny.gov

\author{
Alipour, Alice \\ Department of Civil and Environmental Engineering \\ 234A Marston Hall \\ University of Massachusetts, Amherst \\ 130 Natural Resources Road \\ Amherst, MA 01003-9293, USA \\ Tel: +1-413-577-3184 \\ Email: alipour@umass.edu
}

\section{Arangio, Stefania}

Department of Structural and Geotechnical Engineering

Sapienza University of Rome

Via Eudossiana 18

00184 - Rome, Italy

Tel: +39-0644585072

Email: stefania.arangio@uniroma1.it 


\section{Arteaga-Arcos, Juan Carlos}

Civil Engineering Department, School of Engineering

Autonomous University of Mexico State

Ciudad Universitaria s/n, Cerro de Coatepec

Toluca, Estado de Mexico, 50130, Mexico

Tel: $+52-722-2140855$

Email: jcarteaga_mx@yahoo.com.mx

\section{Bastidas-Arteaga, Emilio}

LUNAM Universite, Universite de Nantes-Ecole Centrale Nantes

GeM, Institute for Research in Civil and Mechanical Engineering

Sea and Littoral Research Institute

44322 Nantes Cedex 3, France

Tel: +33-251125524

Email: emilio.bastidas@univ-nantes.fr

\section{Beer, Michael}

Institute for Risk and Uncertainty \&

Centre for Engineering Sustainability

School of Engineering, University of Liverpool

Brodie Tower, Liverpool, L69 3GQ, UK

Tel: +44-151-7945224

Email: mbeer@liverpool.ac.uk

\section{Biondini, Fabio}

Department of Civil and Environmental Engineering

Politecnico di Milano

Piazza Leonardo da Vinci, 32

20133 Milan, Italy

Tel: +39-02-2399 4394

Email: fabio.biondini@polimi.it

\section{Bjarnadottir, Sigridur}

College of Engineering, Technology, and Architecture

United Technologies Hall - UT Hall 241

University of Hartford

200 Bloomfield Avenue

West Hartford, Connecticut 06117, USA

Tel: +1-860-768-5563

Email: bjarnadot@hartford.edu

\section{Bontempi, Franco}

Department of Structural and Geotechnical Engineering

Sapienza University of Rome

Via Eudossiana 18

00184 - Rome, Italy

Tel: +39-0644585070

Email: franco.bontempi@uniroma1.it 


\section{Brühwiler, Eugen}

Structural Maintenance and Safety Laboratory,

Civil Engineering Institute

School of Architecture, Civil and Environmental Engineering

Swiss Federal Institute of Technology Lausanne

Office: GC B2 386, Station 18, CH-1015 Lausanne, Switzerland

Tel: +41-21-69-32882, +41-21-69-32885

Email: eugen.bruehwiler@epfl.ch

Caetano, Elsa

ViBest, Faculty of Engineering

University of Porto

R. Dr. Roberto Frias, 4200-465 Porto, Portugal

Tel: +351-225081904

Email: ecaetano@fe.up.pt

Casas, Joan R.

Construction Engineering Department

Technical University of Catalonia

Jordi Girona 1-3, North Campus, Building C1

08034 Barcelona, Spain

Tel: +34-934016513

Email: joan.ramon.casas@upc.edu

\section{Cunha, Álvaro}

ViBest, Faculty of Engineering

University of Porto

R. Dr. Roberto Frias, 4200-465 Porto, Portugal

Tel: +351-225081580

Email: acunha@fe.up.pt

da Porto, Francesca

Department of Civil, Environmental and Architectural Engineering

University of Padova

Via Marzolo, 9

35131 Padova, Italy

Tel: +39-049-827-5631

Email: francesca.daporto@unipd.it

\section{De Leon Escobedo, David}

Civil Engineering Department, School of Engineering

Autonomous University of Mexico State

Ciudad Universitaria s/n, Cerro de Coatepec

Toluca, Estado de Mexico, 50130, Mexico

Tel: +52-722-2140855

Email: daviddeleonescobedo@yahoo.gcom.mx 


\section{Delgado-Hernandez, David Joaquín}

Civil Engineering Department, School of Engineering

Autonomous University of Mexico State

Ciudad Universitaria s/n, Cerro de Coatepec

Toluca, Estado de Mexico, 50130, Mexico

Tel: +52-722-2140855

Email: delgadoh01@yahoo.com

\section{Donà, Marco}

Department of Civil, Environmental and Architectural Engineering

University of Padova

Via Marzolo, 9

35131 Padova, Italy

Tel: +39-049-8275625

Email: marco.dona@dicea.unipd.it

\section{Frangopol, Dan M.}

Department of Civil and Environmental Engineering

Center for Advanced Technology for Large Structural Systems (ATLSS Center)

Lehigh University

117 ATLSS Drive, Imbt Labs

Bethlehem, PA 18015-4729, USA

Tel: +1-610-758-6103

Email: dan.frangopol@lehigh.edu

\section{Garbatov, Yordan}

Centre for Marine Technology and Engineering

Instituto Superior Tecnico, Universidade de Lisboa

Av. Rovisco Pais, 1049-001 Lisboa, Portugal

Tel: +351-218417907

Email: Yordan.garbatov@centec.tecnico.ulisboa.pt

\section{Guedes Soares, Carlos}

Centre for Marine Technology and Engineering

Instituto Superior Tecnico, Universidade de Lisboa

Av. Rovisco Pais, 1049-001 Lisboa, Portugal

Tel: +351-218417607\& +351-218417957

Email: c.guedes.soares@centec.tecnico.ulisboa.pt

\section{Kaito, Kiyoyuki}

Division of Global Architecture

Graduate School of Engineering

Osaka University

Building \#S1-613, 2-1 Yamadaoka, Suita

Osaka 565-0871, Japan

Tel: +81-6-6879-7630

Email: kaito@civil.eng.osaka-u.ac.jp 


\section{Kobayashi, Kiyoshi}

Business Administration Chairs

Graduate School of Management

Kyoto University

Yoshidahonmachi, Sakyo-ku

Kyoto 606-8501, Japan

Tel: +81-75-383-3222

Email: kobayashi.kiyoshi.6n@kyoto-u.ac.jp

Kougioumtzoglou, Ioannis A.

Institute for Risk and Uncertainty

\& Centre for Engineering Sustainability

School of Engineering

University of Liverpool

Room 606, Brodie Tower, Brownlow Street

L69 3GQ Liverpool, UK

Tel: +44-151-794-4662

Email: kougioum@liverpool.ac.uk

Labi, Samuel

Lyles School of Civil Engineering

Purdue University

Hampton Hall, 550 Stadium Mall Drive

West Lafayette, IN 47907, USA

Tel: +1-765-494-5926

Email: labi@purdue.edu

\section{Lavrenz, Steven}

Lyles School of Civil Engineering

Purdue University

Hampton Hall, 550 Stadium Mall Drive

West Lafayette, IN 47907, USA

Tel: +1-765-494-2206

Email:slavrenz@purdue.edu

Li, Yue

Department of Civil and Environmental Engineering

Michigan Technological University

1400 Townsend Drive

Houghton, Michigan, 49931, USA

Tel: +1-906-487-1485

Email:yueli@mtu.edu

\section{Madanat, Samer}

Department of Civil and Environmental Engineering Institute of Transportation Studies

763 Davis Hall, University of California, Berkeley

Berkeley, CA 94720-1710, USA

Tel: +1-510-643-8739

Email:madanat@ce.berkeley.edu 
Magalhães, Filipe

ViBest, Faculty of Engineering

University of Porto

R. Dr. Roberto Frias, 4200-465 Porto, Portugal

Tel: +351-225081854

Email: filipema@fe.up.pt

\section{Matsuzaki, Hiroshi}

Department of Civil and Environmental Engineering

Tohoku University

6-6-06 Aramaki-Aza-Aoba Aoba-Ku

Sendai 980-8579, Japan

Tel: +81-22-795-7447

Email: matsuzaki@civil.tohoku.ac.jp

\section{Medury, Aditya}

Safe Transportation Research and Education Center

University of California, Berkeley

2614 Dwight Way

Berkeley, CA 94720-7374, USA

Tel: +1-510-529-8645

Email: amedury@berkeley.edu

\section{Melchers, Robert E.}

Centre for Infrastructure Performance and Reliability

The University of Newcastle

Building EA 117

Callaghan, NSW 2308, Australia

Tel: +61-2-4921-6044

Email: rob.melchers@newcastle.edu.au

\section{Modena, Claudio}

Department of Civil, Environmental and Architectural Engineering University of Padova

Via Marzolo, 9

35131 Padova, Italy

Tel: +39-049-827-5613

E-mail: claudio.modena@unipd.it

\section{Moutinho, Carlos}

ViBest, Faculty of Engineering

University of Porto

R. Dr. Roberto Frias, 4200-465 Porto, Portugal

Tel: +351-225081814

Email: moutinho@fe.up.pt 
Murillo Hoyos, Jackeline

Lyles School of Civil Engineering

Purdue University

Hampton Hall, 550 Stadium Mall Drive

West Lafayette, IN 47907, USA

Tel: +1-765-494-2206

Email: jmurill@purdue.edu

\section{O’Connor, Alan}

Department of Civil, Structural \& Environmental Engineering

Trinity College Dublin

Dublin 2, Ireland

Tel: +353-1-896-1822

Email: oconnoaj@tcd.ie

Obama, Kengo

NEXCO-West Joint Research Chair

Graduate School of Engineering

Osaka University

Building \#TA-B305, 2-8 Yamadaoka, Suita

Osaka 565-0871, Japan

Tel: +81-6-6879-4866

Email: k-obama@civil.eng.osaka-u.ac.jp

Papakonstantinou, Konstantinos G.

Department of Civil Engineering and Engineering Mechanics

Columbia University

630 Seeley W. Mudd

500 West 120th St.

New York, NY 10027, USA

Tel: +1-646-801-6521

Email:kp2570@columbia.edu

Patelli, Edoardo

Institute for Risk and Uncertainty,

School of Engineering, University of Liverpool

Room 612, Brodie Tower

L69 3GQ Liverpool, UK

Tel: +44-151-7944079

Email: edoardo.patelli@liverpool.ac.uk

\section{Pellegrino, Carlo}

Department of Civil, Environmental and Architectural Engineering University of Padova

Via Marzolo, 9

35131 Padova, Italy

Tel: +39-049-8275618

Email: carlo.pellegrino@unipd.it 


\section{Schoefs, Franck}

LUNAM Université, Université de Nantes-Ecole Centrale Nantes

GeM, Institute for Research in Civil and Mechanical Engineering

Sea and Littoral Research Institute

IUML - FR CNRS 3473

Nantes, France

Tel: +33-251-125522

E-mail: franck.schoefs@univ-nantes.fr

\section{Shafei, Behrouz}

Department of Civil and Environmental Engineering

233 Marston Hall

University of Massachusetts, Amherst

130 Natural Resources Road

Amherst, MA 01003-9293, USA

Tel: +1-413-545-0434

Email: shafei@engin.umass.edu

\section{Shinozuka, Masanobu}

Department of Civil Engineering \& Engineering Mechanics

Columbia University

606A Seeley W. Mudd

500 West 120th St.

New York, NY 10027, USA

Tel: +1-212-854-3082

Email:shinozuka@columbia.edu

Söderqvist, Marja-Kaarina

Finnish Transport Agency, Maintenance Department

Infrastructure Technology/Engineering Structures

Bridge Management Systems

P.O. Box 33, Opastinsilta 12 A, FIN-00520 Helsinki, Finland

Tel: + 358-295-34-3613

Email: marja-kaarina.soderqvist@liikennevirasto.fi

Stewart, Mark G.

Centre for Infrastructure Performance and Reliability

School of Engineering

The University of Newcastle

Newcastle, NSW 2308, Australia

Tel: +61-2-4921-6027

Email: Mark.Stewart@newcastle.edu.au

\section{Tecchio, Giovanni}

Department of Civil, Environmental and Architectural Engineering

University of Padova

Via Marzolo, 9

35131 Padova, Italy

Tel: +39-049-8275614

Email: giovanni.tecchio@dicea.unipd.it 
Val, Dimitri V.

Institute for Infrastructure and Environment

School of the Built Environment

Heriot-Watt University

Edinburgh, EH14 4AS, UK

Tel: +44-131-451-4622

Email: d.val@hw.ac.uk

\section{Villalba, Sergi}

Construction Engineering Department

Technical University of Catalonia

C/Colom 11, Edifici TR-5, 08222 Terrassa

Barcelona, Spain

$\&$

CRACK Ingeniería Catalana - COTCA S.A. Partners

Tuset $8,5^{\circ}, 1^{a}$, 08006 Barcelona, Spain

Tel: +34-932187146

Email: sergio.villalba@upc.edu

Villalba, Vicens

Construction Engineering Department

Technical University of Catalonia

C/Jordi Girona 1-3, Campus Nord, Edifici C1

08034 Barcelona, Spain

$\&$

SGS Tecnos S.A.

Llull, 95-97, $5^{a}$ planta

08005 Barcelona, Spain

Tel: +34-933203617

Email: vicente.villalba@upc.edu

\section{Wang, Xiaoming}

Sustainable Cities and Coasts, National Climate Adaptation Flagship

Commonwealth Scientific and Industrial Research Organisation

Highett, Victoria, 3190, Australia

Tel: +61-3-9252-6328

Email: xiaoming.wang@csiro.au

\section{Yanev, Bojidar}

Bridge Inspection and Management

NYC Department of Transportation

55 Water St., New York, NY10041, USA

Tel: +1-212-839-4181

Email: byanev@dot.nyc.gov 
Zanini, Mariano Angelo

Department of Civil, Environmental and Architectural Engineering

University of Padova

Via Marzolo, 9

35131 Padova, Italy

Tel: +39-049-8275585

Email: marianoangelo.zanini@dicea.unipd.it

Zhu, Benjin

Department of Civil and Environmental Engineering

Center for Advanced Technology for Large Structural Systems (ATLSS Center)

Lehigh University

117 ATLSS Drive, Imbt Labs

Bethlehem, PA 18015-4729, USA

Tel: +1-610-758-3527

Email: bez209@lehigh.edu 